\title{
The Effect of Moisture on Gram Differentiation, and its Relation to Proposed Gram-Positive Substrates in Yeast and Other Organisms
}

\author{
BY J. W. BARTHOLOMEW, F. L. TUCKER AND H. FINKELSTEIN \\ Department of Bacteriology, University of Southern California, \\ Los Angeles 7, California, U.S.A.
}

(Received 10 February 1964)

\begin{abstract}
SUMMARY
Wet and dry Gram staining procedures have different characteristics in respect to their rates of decolorization. It has been proposed that this difference is due to a Gram-positive substrate which dissociates (becomes Gram-negative) in the presence of water. However, the differences between wet and dry Gram procedures can also be explained on the hypothesis that water influences the rate of solvent permeation through cell envelopes. Since no direct proof exists for the reality of the proposed Gram-positive substrate, and since evidence is presented here which cannot be explained by such a hypothesis, it is felt that the solvent permeation concept should be considered seriously as an explanation for the decolorization differences observed between wet and dry Gram procedures.
\end{abstract}

\section{INTRODUCTION}

The mechanism of the differentiation of bacterial cells by the Gram staining procedure is not clear. Some believe that Gram differentiation may be a permeability or permeation phenomenon (Benians, 1920; Burke \& Barnes, 1929; Bartholomew, Cromwell \& Finkelstein, 1959; Salton, 1963); some believe it to be due to differences in basic dye uptake (Stearn \& Stearn, 1924; Barbaro \& Kennedy, 1954; Lamanna $\&$ Mallette, 1954); and some believe it to be the result of some specific Gram-positive chemical component in the cell such as lipids (Schumacher, 1928), proteins (Deussen, 1921), nucleic acids (Henry \& Stacey, 1943), carbohydrate (Webb, 1948), sulfhydryl groups (Fischer \& Larose, 1952) and glycerophosphate (teichoic acids; Mitchell \& Moyle, 1950, 1954). This variety of proposed Gram-positive components leads to the suspicion that no single component can adequately explain the phenomenon of Gram positivity.

Chelton \& Jones (1959) supported the concept of a Gram-positive substrate. They observed that ruptured cells of Gram-positive bacteria and yeast would stain Gram-negative when water wet slides were subjected to a Gram procedure, but Gram-positive if a dry slide was processed. Intact cell preparations gave a Grampositive result with either procedure. They proposed, therefore, that Gram-positive organisms contain a substrate which could form a complex with dye and iodine. This complex remained undissociated (Gram-positive) in the presence of $90 \%(\mathrm{v} / \mathrm{v})$ ethanol in water, but became dissociated (Gram-negative) in the presence of more water such as with $70 \%(\mathrm{v} / \mathrm{v})$ ethanol in water. Water wet slides would supply 
sufficient water to dissociate this complex, even though a $90 \%(\mathrm{v} / \mathrm{v})$ ethanol decolorizer was used. Intact cells would not be subjected to this difference between wet and dry slides since their intact cell envelopes enabled them to control the ethanol concentration inside of the cell so that it never fell below $90 \%$. The mechanism of Gram-positivity was interpreted, then, as a combination of the presence of a Gram-positive component, and selective permeability to ethanol of the intact cell envelopes.

Bartholomew (1962) showed that intact cells, both Gram-positive and Gramnegative, were influenced by wet and dry Gram procedures, as well as by the water content of the decolorizer, in respect to the rate of decolorization. This presents the possibility that the differences observed by Chelton \& Jones for ruptured cells can be explained without resorting to the concept of a Gram-positive component. The present paper presents the results of experiments to test this possibility.

\section{METHODS}

In the duplication of the work of Chelton \& Jones (1959) all cell preparations and staining procedures were as described by them. However, since it was desired to have a more quantitative comparison of decolorization characteristics than that used by Chelton \& Jones, a Gram procedure described by Bartholomew (1962) also was used. Briefly, the latter involved the substitution of Hucker's crystal violet for $0.5 \%$ methyl violet $6 \mathrm{~B}$, the use of $95 \%(\mathrm{v} / \mathrm{v})$ ethanol in water as a decolorizer rather than $90 \%(v / v)$ ethanol in water and the use of a quantitative decolorization procedure. The quantitative decolorization procedure used 3 Coplin dishes $(25 \times 75 \mathrm{~mm}$.) each filled with $70 \mathrm{ml}$. of ethanol + water and each used for one third of the total decolorization time, which was varied in each experiment from 5 sec. to $60 \mathrm{~min}$. The water content of the decolorizer was prevented from increasing by use of a dish rotation system, in which after four slides the ethanol water mixture in the first dish was discarded, the dish refilled, and placed last in the sequence.

All organisms were from $24 \mathrm{hr}$ cultures grown on an enriched nutrient agar, except for Clostridium perfringens which was grown on a semi-solid thioglycollate medium, and Saccharomyces cerevisiae which was grown on Sabouraud's agar, or obtained from yeast cakes. Organisms were disintegrated in a Mickle apparatus, with cooling in ice water after every minute of treatment. The time of treatment varied from 8 to $20 \mathrm{~min}$. which was sufficient time, as observed with the microscope, to produce disruption of 90-99\% of the organisms. Centrifugation was done with a Servall Centrifuge at $3000 \mathrm{~g}$ for $15 \mathrm{~min}$., followed by resuspension in ice water. After two such centrifugations and resuspensions in ice water the cell fragments were recentrifuged and only the upper portion of the pellet was resuspended in ice water. This suspension was centrifuged at $3800 \mathrm{~g}$ for $15 \mathrm{~min}$. and the supernatant fluid decanted. After resuspension of the pellet in ice water, the suspension was used for preparation of the slides. In the reproduction of the Chelton \& Jones experiments, the suspensions were very concentrated and resulted in areas in which cell fragments and other cell debris made the slide almost opaque. In our Gram procedures, the cell fragments were diluted so that they did not overlap.

In the dry Gram procedure the smears were treated with crystal violet solution, followed by iodine, washed in water, and then blotted and air dried. Just before 
passage of these slides through the decolorizer, they were lightly flamed and cooled. In the wet Gram procedure, the smears were treated with crystal violet solution, iodine, then washed in water and processed wet through the decolorizer. In some experiments it was desired to have wet smears, but with no excess of water on the surface of the slide. For this, a modified wet Gram procedure was used. This consisted of staining the slides with crystal violet, treating with iodine, washing and then thoroughly drying. Following this, the slide was exposed to a strip of No. 1 Whatman filter-paper saturated with water. This wet filter-paper was pressed to the surface of the smear to assure moisture contact, and removed just before decolorization.

A Beckman model DB automatic recording spectrophotometer was used to obtain the light extinction curves.

\section{RESULTS}

The wet and dry Gram procedures gave different results for ruptured yeast cells, as reported by Chelton \& Jones (1959). The last line of results in Table 1 shows that when using their procedure (procedure II, Table 1) ruptured yeast cells were Grampositive when a dry procedure was used, but were Gram-negative when a wet procedure was used. Almost identical results were obtained, for a $2 \mathrm{~min}$. decolorization time, when a quantitative Gram procedure (procedure I, Table 1) was used. The quantitative procedure, however, showed several additional facts. When the decolorization time was reduced to $15 \mathrm{sec}$. for the wet procedure, the yeast cell fragments could then be considered to be Gram-positive (as compared with the control organisms) despite the Gram-negative results obtained with a 2 min. decolorization time. Also, despite the Gram-positive nature of the ruptured yeast cells following a dry Gram procedure and a 2 min. decolorization time, they were Gramnegative following a $30 \mathrm{~min}$. decolorization time. It was thus clear that the Grampositive or Gram-negative characteristic of ruptured yeast cells, following a wet or dry Gram procedure, was a quantitative rather than a qualitatively determined characteristic.

Chelton \& Jones reported that ruptured yeast cells stained Gram-negative with a dry Gram procedure when $70 \%(\mathrm{v} / \mathrm{v})$ ethanol in water was used as a decolorizer. They suggested that the $70 \%(\mathrm{v} / \mathrm{v})$ ethanol in water supplied sufficient water to allow the dissociation of the Gram-positive complex. It can be seen in Table 2 that when a dry Gram procedure and a $2 \mathrm{~min}$. decolorization time were used ruptured yeast cells were Gram-negative when $70 \%(v / v)$ ethanol in water was used as decolorizer. However, by decreasing the decolorization time to $30 \mathrm{sec}$, the ruptured cells were Gram-positive. According to the Chelton \& Jones concept, a wet Gram procedure also using $\mathbf{7 0} \%(\mathrm{v} / \mathrm{v})$ ethanol in water as decolorizer would have two exposures to water sufficient to produce a Gram-negative result for ruptured yeast cells. Yet Table 2 shows that such a procedure produced a Gram-positive result when the decolorization time was decreased to $15 \mathrm{sec}$. It would appear that Gram differentiation was not solely a function of the effect of water on the presence or absence of a Gram-positive complex, but would be at least in part a function of the proper choice of a decolorization time to compensate for factors which influence rate of decolorization.

Chelton \& Jones interpreted the Gram-negative results for ruptured yeast cells stained by a wet Gram procedure as due to the dilution of the decolorizer by the 
हूँ

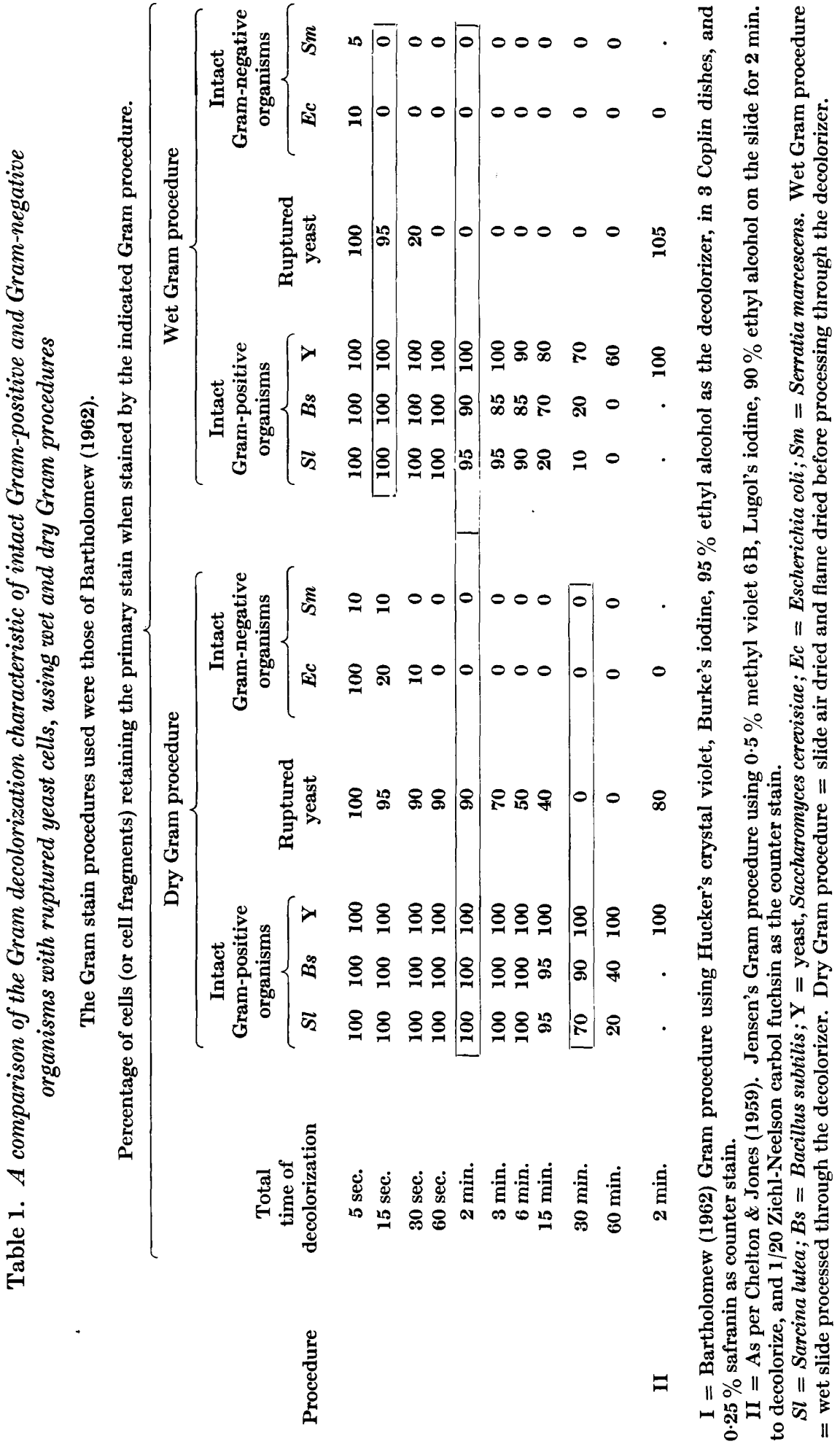




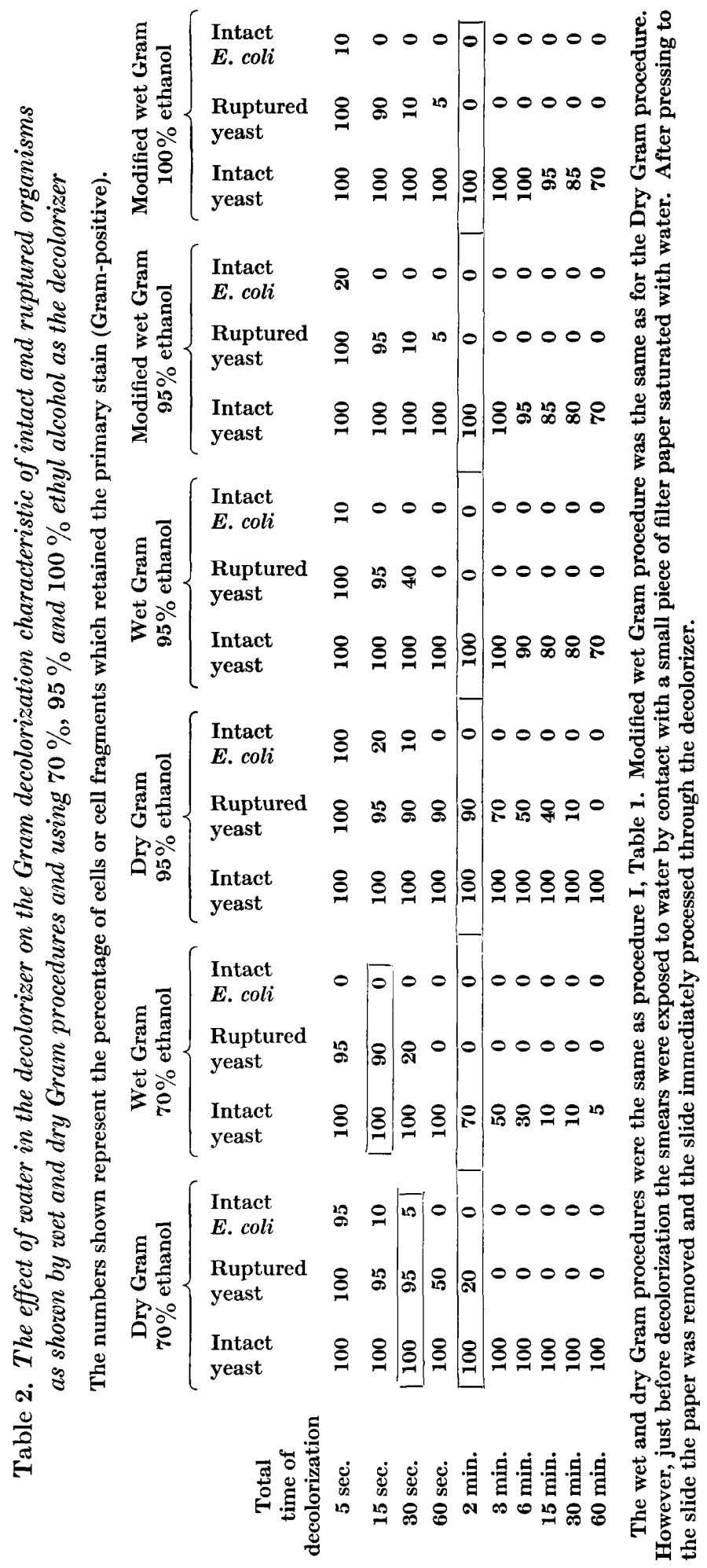


262 J. W. Bartholomew, F. L. Tucker and H. Finkelstein

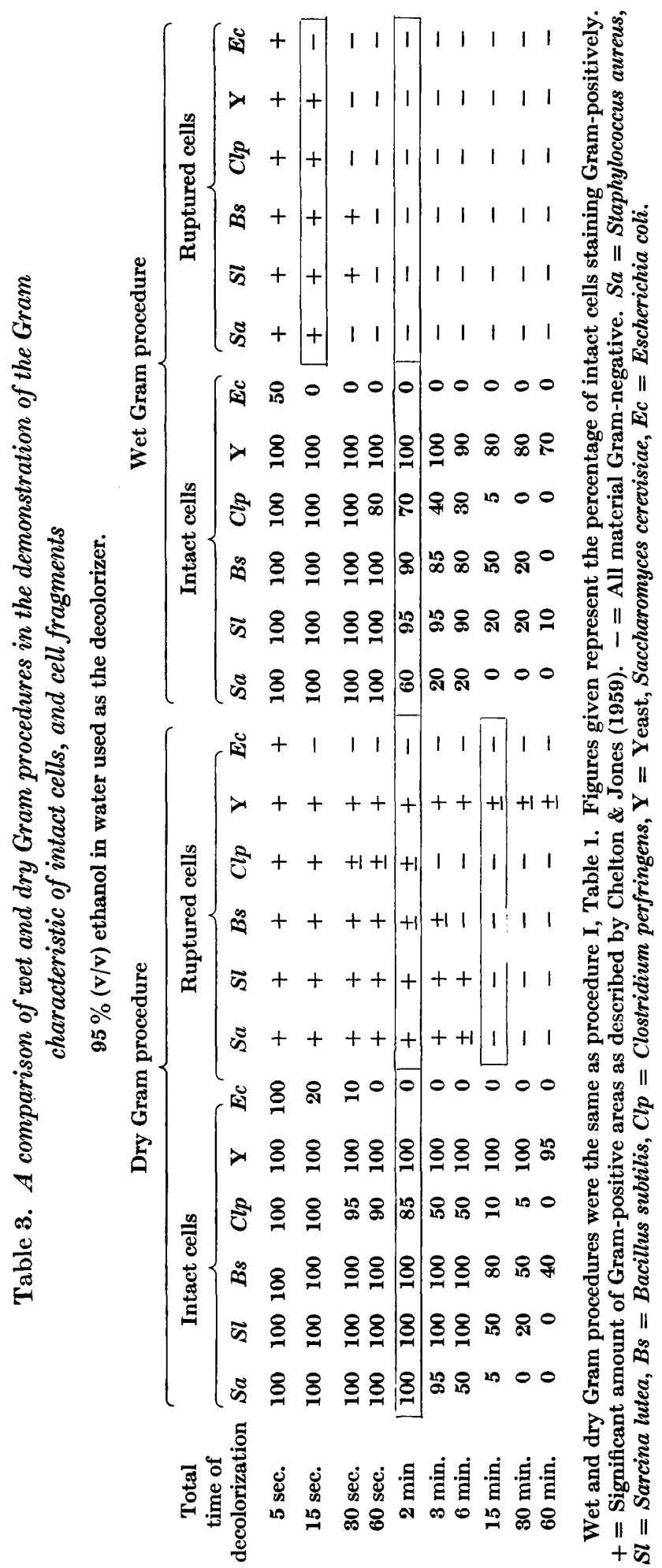


water on the slide, such dilution supposedly resulting in dissociation of the Grampositive complex. The wet Gram procedure was therefore modified to assure that the decolorizer was in no significant way diluted by water from the slide. The slide itself was dry except for the smear area which had been exposed to wet filter-paper. The slide was then processed through three Coplin dishes, each containing $70 \mathrm{ml}$. of $95 \%(\mathrm{v} / \mathrm{v})$ ethanol in water in some experiments, and absolute ethanol in other experiments. It would have been impossible for the water in the cells to have diluted the $95 \%$ or $100 \%$ ethanol to any significant degree. Yet under these conditions, as shown in Table 2, the results were typical for the usual wet procedure. Certainly, the decolorization differences observed between the modified wet procedures and dry procedure cannot be explained by water dilution of the decolorizer.

Table 3 presents the results obtained with intact and ruptured organisms of many species of Gram-positive bacteria, as compared with Escherichia coli. With the 2 min. decolorization time of Chelton \& Jones, and $95 \%(v / v)$ ethanol in water as decolorizer, the ruptured organisms were Gram-positive with a dry Gram procedure and Gram-negative with a wet procedure, as Chelton \& Jones would have predicted. However, whether ruptured organisms were Gram-positive or Gram-negative depended on the decolorization time. With the dry Gram procedure, ruptured organisms were Gram-positive with a 2 min. decolorization time, but Gram-negative with a decolorization time of $15 \mathrm{~min}$. or longer. With the wet Gram procedure, ruptured organisms were Gram-negative for a $2 \mathrm{~min}$. decolorization time, but Grampositive for a $15 \mathrm{sec}$. decolorization time. It would thus appear that, as for intact and ruptured yeast cells, the length of the decolorization time was more relevant to Gram differentiation than was the presence or absence of water in the smear. Our results which show the proper Gram differentiation of ruptured Gram-positive organisms are of particular interest since it has often been reported that such ruptured organisms are Gram-negative (Benians, 1912, 1920; Burke \& Barnes, 1929). It can be seen (Table 3 ) that such differentiation would not have been detected if a wet Gram procedure were used with a single $2 \mathrm{~min}$. decolorization time. However, it was detected with either a wet or dry Gram procedure, when a quantitative decolorization procedure was used. The ability to properly differentiate ruptured organisms demonstrates the fact that the cell envelopes by themselves could be an important contributing factor to Gram differentiation.

Chelton \& Jones (1959) further supported their concept of a Gram-positive substrate as part of the mechanism of Gram positivity by presenting evidence which they believed disproved the concepts involving permeability. They (also Burke, 1922) reported that ethanolic solutions of the dye iodine precipitate would stain intact Gram-positive organisms. This was interpreted as showing that the large dye iodine molecule could permeate through the envelopes of Gram-positive organisms, therefore no permeability barrier to it existed. Such a barrier to the loss of the dye iodine precipitate inside of a Gram-positive organism, therefore, could not be used to explain the mechanism of Gram positivity. While such a barrier has been proposed (Benians, 1920; Burke \& Barnes, 1929), this concept has long been discounted by Stearn \& Stearn (1930) who reported that ethanolic solutions of the precipitate gave identical light extinction peaks as for ethanolic solutions of the iodine and crystal violet alone. This, along with boiling point data, led them to conclude that no new molecule was produced on precipitate formation, which on redissolution in ethanol 


\section{J. W. Bartholomew, F. L. Tucker and H. Finkelstein}

did not revert to the original dye and iodine molecules as independent entities. Stearn \& Stearn did not publish light extinction curves and therefore such curves are shown in Fig. 1. It can be seen that the extinction curves for Burke's iodine, or crystal violet alone, were identical with those obtained when the dye iodine precipitate was dissolved in ethanol. Thus, the ability of ethanolic solutions of the precipitate

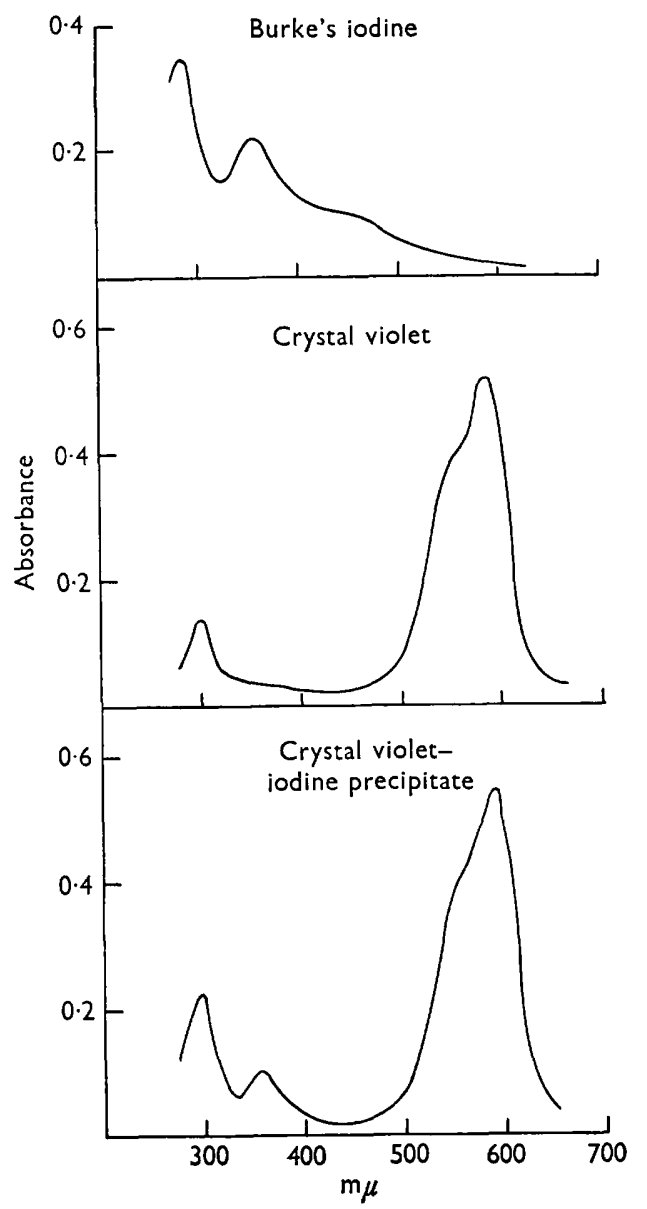

Fig. 1. Extinction spectra of Burke's iodine, crystal violet, and crystal violet + Burke's iodine precipitate dissolved in $95 \%(v / v)$ ethanol in water.

to stain intact Gram-positive organisms would not be evidence against a permeability concept since the hypothetical large dye iodine molecule does not exist in ethanolic solutions. However, the non-existence of such a large dye iodine molecule does not destroy all permeability concepts, since permeability differences could exist for the dye or iodine molecules alone, or for the solvent itself. 


\section{DISCUSSION}

It is not necessary to propose a Gram-positive component with the dissociation characteristics suggested by Chelton \& Jones (1959) to explain the differences in decolorization speeds of wet and dry Gram procedures. Another explanation would be that water in the cell envelopes, or in the decolorizer, could have a marked speeding effect on decolorization. That water has this effect can be well documented (Benians, 1920; Burke, 1922; Burke \& Barnes, 1929; Wensinck \& Boevé, 1957; Tucker \& Bartholomew, 1962; Bartholomew, 1962). Thus, if a single decolorization time were used for both wet and dry Gram procedures (as Chelton \& Jones) the results obtained might be misleading concerning the Gram nature of an unknown, even though comparisons were made with known organisms. Table 1 shows that when a single 2 min. decolorization time was used, ruptured yeast cells appeared to be Grampositive with a dry procedure, and Gram-negative with a wet, as compared to known controls. However, had a $15 \mathrm{sec}$. decolorization time been used, ruptured yeast cells would have appeared to be Gram-positive, and if a $30 \mathrm{~min}$. time had been used Gram-negative, with both wet and dry procedures. In both examples, although the opposite Gram results were obtained the results appeared to be valid as compared to the control organisms included in the experiments. The Gram-positive (dry) and Gram-negative (wet) results reported by Chelton \& Jones for ruptured yeast cells, then, were the result of the choice of a single decolorization time for two very different Gram procedures, rather than to any real change from a Gram-positive to a Gramnegative state. The true state of affairs as to the Gram nature of ruptured yeast cells is shown in Tables 1-3. Here it can be seen that with either wet or dry procedures ruptured cells of Gram-positive organisms decolorized faster than corresponding intact cells, and slower than either the intact or ruptured cells of Gram-negative organisms. Thus, the ruptured cells were more Gram-positive than intact Gramnegative cells, but more Gram-negative than intact Gram-positive cells. This fact could not be determined from the results obtained with only one decolorization time, but could be determined only by comparing the results obtained from a series of decolorization times. The question which arises then, is what criteria can be used to evaluate the validity of results obtained with any single Gram procedure. The answer is simple if one is only concerned with intact cells and if one closely follows the ordinarily recommended Gram procedures (Bartholomew, 1962). However, if one studies ruptured organisms, or used heat in staining, or changes the decolorizer or decolorization procedure, and if at the same time one sticks to a single decolorization time, then all that emerges blue is not necessarily Gram-positive. Some of the criteria for the recognition of true Gram-positivity (in addition to rate comparisons) have been presented by Bartholomew, Mittwer \& Finkelstein (1959).

A Gram-positive substrate, with the dissociation characteristics proposed by Chelton \& Jones, was not confirmed by our results. Wet Gram procedures which prevented any significant water dilution of a $100 \%$ ethanol decolorizer gave results (Table 2, modified wet Gram) as expected for wet procedures, not dry. Thus, the rapid decolorization effect of 'wet' procedures could not be due merely to the dissociation of a Gram-positive complex when exposed to ethanol (70\%, v/v) diluted by water. Furthermore if, as proposed, the Gram-positive substrate is dissociated in the presence of $70 \%(v / v)$ ethanol in water, then when such a decolo- 


\section{J. W. Bartholomew, F. L. Tucker and H. Finkelstein}

rizer is used it should not be possible to obtain a Gram-positive result for ruptured yeast cells. Yet Table 2 shows that this result could be obtained for both wet (15 sec. decolorization) and dry (30 sec. decolorization) Gram procedures. Our results do not support the suggestion that intact Gram-positive organisms would not be influenced by water in the decolorizer because of their ability to control the ethanol concentration inside of the cell. If this were true then intact Gram-positive organisms should not be influenced in their decolorization rate by wet or dry Gram procedures, or by water in the ethanol decolorizer. Our results, however, showed that all organisms, intact or ruptured, Gram-positive or Gram-negative, were decolorized more rapidly by a wet than by a dry Gram procedure. A very conclusive argument against the formation of a Gram-positive substrate dye iodine complex is the fact that it has been demonstrated that cells stained with iodine alone (Bartholomew, Cromwell \& Finkelstein, 1959) or dye alone (Benians, 1920; Bartholomew \& Mittwer, 1950) could be properly Gram differentiated if care were taken with the decolorization procedure. Thus, the Gram-positive characteristic could not be due entirely to any such proposed complex.

If a dissociating Gram-positive complex is not responsible for the differences between wet and dry Gram procedures, how can the differences be explained? They can be explained by a concept involving the permeation rate of solvent through cell envelopes. If the dye iodine precipitate were dispersed through the whole cell or cell fragments, and if ethanol permeated the cell envelopes of Gram-positive organisms, then ruptured as well as intact Gram-positive organisms should reflect this difference in their speed of decolorization. That is, intact organisms would decolorize slower than ruptured organisms due to the lesser cell envelope surface exposed for ethanol permeation, and to the greater amounts of dye iodine precipitate present in the intact cell as compared to the fragmented envelopes. Intact or fragmented Gram-positive organisms would be slower to decolorize than intact or fragmented Gram-negative organisms since the envelopes of Gram-negative organisms possess very little resistance to ethanol permeation.

Finally, Gram differentiation is basically a rate difference in the speed of decolorization between Gram-positive and Gram-negative organisms. Therefore, under conditions where fine differences must be detected, this rate difference must be quantitatively determined. Such quantitative determinations are not possible using the usual Gram procedures with a single decolorization time. If all of the known variables of the Gram stain procedure were kept constant (Bartholomew, 1962), then a single decolorization time known to give valid differentiations could be used with a fair degree of confidence. If, however, the known variables are changed, and if determinations of the Gram nature of an unknown substrate under different conditions are to be made, then the only valid experimental procedure is to use some form of a quantitative Gram procedure.

The work reported in this paper was supported in part by a research grant E-121 from the National Institutes of Health, U.S. Public Health Service. 


\section{Effect of moisture on Gram differentiation}

\section{REFERENCES}

Barbaro, J. F. \& Kennedy, E. R. (1954). A quantitative Gram reaction. J. Bact. 67, 603.

Bartholomew, J. W. (1962). Variables influencing results, and the precise definition of steps in Gram staining as a means of standardizing the results obtained. Stain Tech. 37, 139.

Bartholomew, J. W., Cromwell, T. \& Finkelstein, H. (1959). A correlation between iodine permeability and the Gram characteristic of cells. Nature, Lond. 183, 123.

Bartholomew, J. W. \& Mrtwwer, T. (1950). The mechanism of the Gram reaction. I. The specificity of the primary dye. Stain Tech. 25, 103.

Bartholomew, J. W., Mittwer, T. \& Finkelstein, H. (1959). The phenomenon of Gram-positivity: its definition and some negative evidence on the causative role of sulfhydryl groups. Stain Tech. 34, 147.

Benians, T. H. C. (1912). Observations on the Gram-positive and acid-fast properties of bacteria. J. Path. Bact. 17, 199.

Benians, T. H. C. (1920). A further investigation into the principles underlying Gram's stain, with special reference to the bacterial cell membrane. J. Path. Bact. 23, 401.

Burke, V. (1922). Notes on the Gram stain with description of a new method. J. Bact. $7,159$.

Burke, V. \& Barnes, M. (1929). The cell wall and the Gram reaction. J. Bact. 18, 69.

Chelton, E. T. J. \& Jones, A. S. (1959). The Gram-staining reaction of disintegrated microorganisms. J. gen. Microbiol. 21, 652.

Deussen, E. (1921). Die Gramsche Bakterienfärbung, ihr Wesen und ihre Bedeutung. Z. Hyg. Infekt.-Kr. 93, 512.

Fischer, R. \& Larose, P. (1952). Mechanism of Gram stain reversal. J. Bact. 64, 435.

Henry, H. \& Stacey, M. (1943). Histochemistry of the Gram reaction for micro-organisms. Nature, Lond. 151, 671.

Lamanna, C. \& Mallette, M. F. (1954). The cytological basis for the role of the primary dye in the Gram stain. J. Bact. 68, 509.

Mitchell, P. \& Moyle, J. (1950). Occurrence of a phosphoric ester in certain bacteria: its relation to Gram staining and penicillin sensitivity. Nature, Lond. 166, 218.

Mitcheld, P. \& Moyle, J. (1954). The Gram reaction and cell composition: nucleic acids and other phosphate fractions. J. gen. Microbiol. 10, 533.

Salton, M. R. J. (1963). The relationship between the nature of the cell wall and the Gram stain. J. gen. Microbiol. 30, 223.

Schumacher, J. (1928). Zur Gramschen Färbung. Über die chemische Zusammensetzung der Lipoidsäure und über künstlich grampositiv gemachte Hefezellen. Z Zbl. Bakt. (Abt. 1. Orig.) 109, 181.

Stearn, A. E. \& Stearn, E. W. (1930). The nature of the Gram compound and its bearing on the mechanism of staining. J. Bact. $20,287$.

Stearn, W. W. \& Stearn, A. E. (1924). The chemical mechanisms of bacterial behaviour. I. Behaviour toward dye-factors controlling Gram reaction. J. Bact. 9, 463.

Tucker, F. L. \& Bartholomew, J. W. (1962). Variations in the Gram staining results caused by air moisture. Stain Tech. 37, 157.

WeBB, M. (1948). The action of lysozyme on heat-killed Gram-positive micro-organisms. J. gen. Microbiol. 2, 260.

Wensinck, F. \& BoEvé, J. J. (1957). Quantitative analysis of the Gram reaction. J. gen. Microbiol. 17, 401. 